\title{
Global Health Curricula in Ophthalmology Residency Programs in the United States
}

\author{
Momoko K. Ponsetto, BS ${ }^{1} \quad$ Nicole H. Siegel, MD ${ }^{1} \quad$ Manishi A. Desai, MD ${ }^{1} \quad$ Kara C. LaMattina, MD ${ }^{1}$ \\ ${ }^{1}$ Department of Ophthalmology, Boston University School of \\ Medicine, Boston, Massachusetts \\ Address for correspondence Momoko K. Ponsetto, BS, Department of \\ Ophthalmology, Boston University School of Medicine, 85 E. Concord \\ J Acad Ophthalmol 2021;13:e183-e191. \\ Street, 8th Floor, Boston, MA 02118 (e-mail: Mkponset@bu.edu).
}

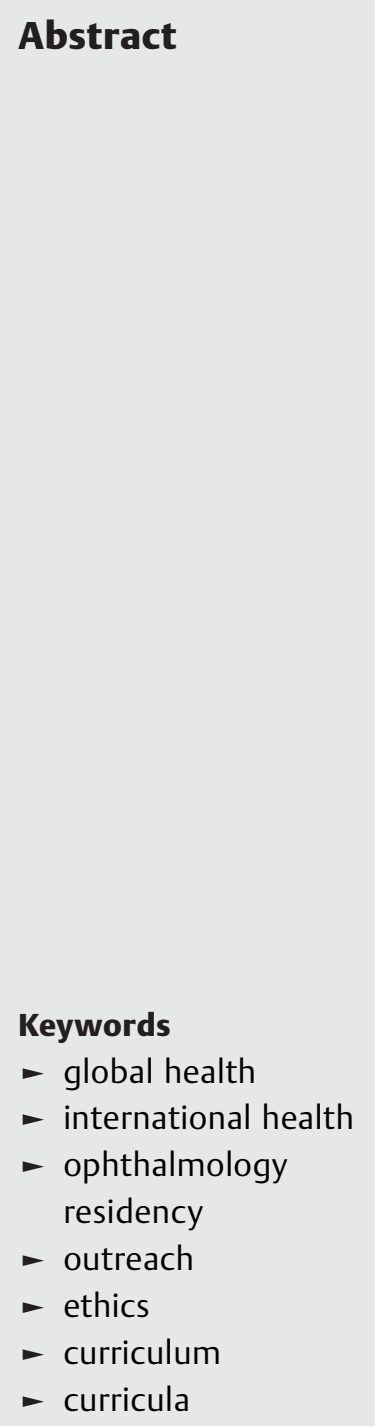

Objective The aim of the study is to investigate the design, content, and administration of global health curricula within ophthalmology residency programs in the United States (U.S.) and share the curriculum utilized in the Department of Ophthalmology at Boston University School of Medicine (BUSM).

Design A survey designed through the Association of University Professors in Ophthalmology platform was emailed to residency program directors at 106 accredited ophthalmology residency programs.

Setting BUSM Department of Ophthalmology, Boston, MA. Tertiary clinical care.

Participants Twenty-eight ophthalmology residency program directors responded, which represent $26 \%$ of the total number of residency programs in the United States. Twenty-seven programs fully completed the survey, and one program partially completed the survey.

Results Of the respondents, three programs do not include global health curricula. The most common curricular elements included are: lectures $(n=15,60 \%)$; wet laboratories ( $n=10,40 \%)$; and journal clubs $(n=9,36 \%)$. In terms of annual frequency, global health activities occur: twice a year $(n=12,46 \%)$; less than once a year $(n=10$, $39 \%)$; or every few months $(n=4,15 \%)$. Fewer than half of programs $(n=10,42 \%)$ incorporate local outreach at least once a year into their program. Twelve programs (48\%) do not incorporate ethics-related topics, while the 13 remaining programs (52\%) incorporate them at least once annually. The most common curricular topic is surgical techniques, with manual small incision cataract surgery (MSICS) being the most frequently emphasized ( $n=17,68 \%$ ).

Conclusion A robust global health curricula combined with a hands-on international component can contribute to a well-rounded training experience. Many ophthalmology residency programs value the importance of incorporating global health into their residents' training. The most common elements of global health curricula in U.S. ophthalmology residency programs included are teaching of surgical techniques for resource-limited settings and international electives. Further investigation into the impact of different components of a global health curriculum on both resident experience and international partnerships is warranted. received

January 24, 2021 accepted after revision July 30, 2021
DOI https://doi.org/ $10.1055 / \mathrm{s}-0041-1736434$. ISSN 2475-4757. (c) 2021. The Author(s).

This is an open access article published by Thieme under the terms of the Creative Commons Attribution-NonDerivative-NonCommercial-License, permitting copying and reproduction so long as the original work is given appropriate credit. Contents may not be used for commercial purposes, or adapted, remixed, transformed or built upon. (https://creativecommons.org/ licenses/by-nc-nd/4.0/)

Thieme Medical Publishers, Inc., 333 Seventh Avenue, 18th Floor, New York, NY 10001, USA 
The integration of global health topics into medical education and residency training has become increasingly prevalent. ${ }^{1,2}$ Many residency programs and medical schools offer curricula and experiences in global health, with as many as $24.2 \%$ of United States (U.S.) medical school graduates having participated in global health experiences in 2019. ${ }^{1}$ Studies have shown that residents across various specialties gain numerous benefits through participation in international health electives. ${ }^{3-6}$ A designated global health curriculum can further a resident's skills in the six core competencies outlined by the Accreditation Council for Graduate Medical Education (ACGME): patient care, medical knowledge, interpersonal and communication skills, professionalism, practice-based learning, and systems-based practice. ${ }^{7-10}$

When investigating potential barriers into the integration of global health education into U.S. ophthalmology residency programs, Coombs and colleagues found that insufficient financial support, inadequate resident coverage at home institutions, and lack of ACGME approval for international electives, did not deter program directors from wanting to further develop their global health programs. ${ }^{11}$ In addition to ophthalmology, these findings have been replicated in other fields such as pediatrics and general surgery. ${ }^{12-14}$ Coombs et al and Camacci et al advocated for a need for global health didactic material beyond what is covered in the standard ophthalmology residency curriculum. ${ }^{11,15}$

Though the administration of international electives in ophthalmology has been studied, little is known about the content of global health curricula within residency programs beyond the international experiences. The objective of this study is to identify the aspects of global health curricula that are currently in place across U.S. residency programs and how frequently they are utilized. This manuscript also includes our global health curriculum from the Department of Ophthalmology at Boston University School of Medicine (BUSM), which incorporates didactics, journal clubs, wet laboratories, local outreach, and international electives. We feel that this diverse curriculum provides residents with the tools to continue to practice high quality, ethical care for international work during and beyond their residency training.

\section{Materials and Methods}

A survey was developed utilizing the Association of University Professors in Ophthalmology (AUPO) platform to investigate the design, content, and barriers of global health curricula in ophthalmology residency programs in the United States. The survey consisted of 14 multiple-choice questions and one free text response ( $\mathbf{- F i g . 1}$ ). This format was chosen to make the survey as succinct as possible to encourage participation. The survey and its aims were approved by the AUPO Data Resource Committee, and in accordance with its guidelines, was administered via an online survey using SurveyGizmo (www.surveygizmo.com) and open for a 2-week period.

The program directors at 106 ACGME-accredited ophthalmology residency programs were invited to participate in the online survey through the AUPO listserve in September 2020, which included a brief description of the project and consent statement. Given the online administration and lack of other incentives, our predicted response rate was approximately $30 \%$ (though researchers were unable to estimate the effect the COVID pandemic would have on response rate at the time of administration). ${ }^{16,17}$ The study was conducted with approval from the Investigational Review Board (IRB) at Boston Medical Center.

\section{Results}

\section{Demographics}

A total of 28 program directors (26\%) responded to the survey. Of the 28 survey responses, 27 were completed and one was partially completed. The locations of the residency programs were geographically diverse, but fairly evenly distributed by region. We received responses from nine program directors from the South (32\%), eight in the Northeast (29\%), six in the Midwest (21\%), and five from the West (18\%). Of these residency programs, 18 programs (64\%) have 7 to 16 total residents, seven programs (25\%) have more than 17 total residents, and three programs (11\%) have zero to six total residents ( $\mathbf{- T a b l e ~} \mathbf{1}$ ).

\section{Resident Participation}

Of the 28 survey participants, 25 programs (89\%) include some aspect of global health including didactics, clinical, and/or research experiences. Of the three programs that do not have global health included in their program, the primary barriers are resident training time (two programs) and low awareness on how to create such a program (one program). Twenty-four programs reported that global health curricula are not mandatory, while two programs have mandatory global health curricula.

In terms of resident participation in the global health curricula, eight programs estimate less than $20 \%$ of residents participate, six programs estimate 81 to $100 \%$ of residents participate, five programs estimate 21 to $40 \%$ of residents participate, three programs estimate 61 to $80 \%$ of residents participate, and two programs estimate 41 to $60 \%$ residents participate (-Fig. 2 ).

\section{International Electives}

Most respondents report offering an international elective (21 programs, $81 \%$ ) as part of their global heath curriculum. Five programs (19\%) do not offer an international elective. The home program's institution and/or department faculty supervise the international experience at 13 programs (62\%), and host/local faculty from the international site act as supervisors for the remaining eight programs (38\%). The most common site for international electives is India (five programs). Other locations include Myanmar, Lesotho, Angola, the Dominican Republic, Eswatini, China, Nepal, Micronesia, Haiti, Tanzania, Kenya, Belize, Guyana, Honduras, and Ethiopia.

Eleven programs (44\%) have international surgical experiences that occur less than once a year, eight programs (32\%) have experiences 1 to 2 times a year, four programs 
1. In which of the following regions is your program located
a. Northeast (New Hampshire, Massachusetts, Rhode Island, Connecticut, New York, Pennsylvania, New Jersey)
b. Midwest (Wisconsin, Michigan, Illinois, Indiana, Ohio, Nebraska, Minnesota, lowa)
c. South (Maryland, District of Columbia, Virginia, West Virginia, North Carolina, South Carolina, Georgia, Florida, Missouri, Kentucky, Tennessee, Mississippi, Alabama, Oklahoma, Texas, Arkansas, Louisiana)
d. West (Utah, Colorado, Arizona, Washington, Oregon, California)

2. Total number of residents in the program

3. Does your residency program include any aspect of global health (didactic, clinical and or research)?
a. YES
b. NO

If yes, please continue

4. Is global health formally included in your educational curriculum (goals and objectives)?
a. YES
b. NO

If yes, please go to 6

5. If no, what is the primary barrier that prevents global health from being incorporated in your curriculum
a. Not a focus of our program
b. Limitations in resident training time
c. Low awareness on how to create such a program
d. Lack of department support
e. Lack of institutional support
f. Lack of international partners

6. Is your global health curriculum mandatory?
a. YES
b. NO

If no, what percentage of your residents participate?

7. How frequent are your global-health related activities?
a. Once a month or more
b. Every few months
c. Twice a year
d. Less than once a year

8. Does your global health curriculum offer an international elective?
a. YES
b. NO

If yes, how is the experience supervised?
a. Your institutional/department faculty
b. Host or local faculty (from international site)
c. Volunteer ophthalmologist

Fig. 1 Online survey for ophthalmology residency program directors. 
If yes, where is the international elective located? (Free text)

9. Does your global health curriculum include global health lectures, journal clubs, and/or wet labs (Click all that apply)?
a. Global Health Lectures
b. Journal clubs
c. Wet labs
d. Other

10. Does your global health curriculum include participation in local outreach programs?
a. Three or more times a year
b. One to two times a year
c. Less than once a year
d. No local outreach programs are included

11. Does your global health curriculum include ethics related topics?
a. Three or more times a year
b. One to two times a year
c. Less than once a year
d. No ethics related topics included in curriculum

12. Does your global health curriculum include surgical exposure?
a. Three or more times year
b. One to two times year
c. Less than once a year
d. No surgical exposure included in curriculum

13. What is the focus of your global health curriculum? Please check all that apply
a. Ethics of global health
b. Unique pathology in global health
c. Strategies for working in resource-limited environments
d. Surgical techniques such as manual small incision cataract surgery
e. Epidemiology research collaborations
f. Disease specific research
g. Local workforce skills transfer
h. Education and resource support
i. Other

Fig. 1 (Continued)

(16\%) have no surgical exposure included in the curricula, and two programs (8\%) have experiences three or more times a year.

\section{Curricular Content}

In terms of frequency of global health-related activities, 12 programs (46\%) offer activities twice a year, 10 programs (39\%) have activities less than once a year, and four programs (15\%) have activities every few months. In terms of participation in local outreach, 14 programs (58\%) do not include local outreach, five programs (21\%) have local outreach one to two times a year, and five programs (21\%) have local outreach three or more times a year.
Lectures are the most frequently incorporated element of all global health curricula in 15 programs (60\%), followed by wet laboratories, which are incorporated by 10 programs (40\%), journal clubs by nine programs (36\%), and other activities by five programs (20\%).

Ethics-related topics are not included in the curriculum of 12 programs (48\%). Six programs (24\%) incorporate ethics 1 to 2 times/year, five programs $(20 \%)<1$ time/y, and two programs ( $8 \%$ ) incorporate $\geq 3$ times/y ( - Fig. 3 ).

The focus of the curricula is widely variable ( - Fig. 4). The most common topic covered is surgical techniques; manual small incision cataract surgery (MSICS) is taught at 17 programs (68\%). Other topics include local workforce skills 
Table 1 Demographics of survey participants

\begin{tabular}{|l|l|}
\hline & Number of programs (\%) \\
\hline Number of program directors responding to survey & 28 \\
\hline Completed survey & 27 \\
\hline Partially completed survey & 1 \\
\hline Locations & \\
\hline $\begin{array}{l}\text { Northeast (New Hampshire, Massachusetts, Rhode Island, Connecticut, New York, } \\
\text { Pennsylvania, New Jersey) }\end{array}$ & 8 (29\%) \\
\hline Midwest (Wisconsin, Michigan, Illinois, Indiana, Ohio Nebraska, Minnesota, lowa) & $6(21 \%)$ \\
\hline $\begin{array}{l}\text { South (Maryland, District of Columba, Virginia, West Virginia, North Carolina, South Carolina, } \\
\text { Georgia, Florida, Missouri, Kentucky, Tennessee, Mississippi, Alabama, Oklahoma, Texas, } \\
\text { Arkansas, Louisiana }\end{array}$ & 9 (32\%) \\
\hline \begin{tabular}{l} 
West (Utah, Colorado, Arizona, Washington, Oregon, California) \\
\hline Number of residents
\end{tabular} & 5 (18\%) \\
\hline $\begin{array}{l}\text { 0-6 residents } \\
\text { 7-16 residents }\end{array}$ & $3(11 \%)$ \\
\hline \begin{tabular}{l} 
17+ residents \\
\hline
\end{tabular} & $18(64 \%)$ \\
\hline
\end{tabular}

transfer and education and resources support at 15 programs (60\%) each, strategies for working in resource-limited environments at 14 programs (56\%), unique pathology in global health at eight programs (32\%), epidemiology research collaborations at seven programs (28\%), ethics of global health at six programs (24\%), disease-specific research at three programs (12\%), and other unspecified topics at five programs (20\%).

\section{Discussion and Conclusion}

Previous studies on the global health education in ophthalmology residency training programs have examined aspects of the international elective itself and cited a need for guidance on global health curricula beyond what is provided by the standard ophthalmology residency program. ${ }^{11,15}$ Our survey is consistent with that of Camacci et al, finding that inclusion of an international elective remains popular (81 and $89 \%$ of respondents, respectively). ${ }^{15}$

Resident time constraints are an often-cited barrier to establishing more involved global health curricula and international electives. ${ }^{11-14}$ This may explain why the majority of the programs that have a global health curriculum, in our study, only have one to two activities per year (85\%). Similar to findings of Camacci et al, we found that program directors prioritized inclusion of global health-related ethics, surgical techniques, and cross-cultural interactions in their global health curriculum. The respondents to our survey also recognize the importance of the ethical implications of global health work, with $52 \%$ of programs already focusing on this topic within their curriculum. Preparation can help residents develop a framework to process the experiences and ethical challenges in their practice both at home and abroad; this can be done through informal discussion, formal didactics, case studies, or simulation. ${ }^{18-20}$ Few studies have investigated the design and content details of global health curricula. Justin et al describes responses from 12 U.S. ophthalmology residency programs regarding broad didactic topics, goals, and services provided in their global health outreach, and understanding of host country health systems. ${ }^{21}$ The study prompts further questions regarding delivery methods for didactic content and best practices to prepare residents for global health work. Of our survey respondents, lectures are the most incorporated aspect of the curriculum at 15 programs (60\%), followed by wet laboratories and journal clubs. Having varied formats of delivering curricular content could cater to different learning styles as well as allowing a wide range of topics to be covered.

Diverse global health curricula with nonpractical and practical components at home institutions would allow for the most complete experience while taking into account program time and travel constraints. Previous studies have not investigated inclusion of local outreach in global health curricula for ophthalmology residencies. Local outreach, for our purposes, can be defined as an experience designed in partnership with underserved communities in the surrounding area of the home institution. Since many international global health opportunities require skills in interacting with underserved populations, having an opportunity for local outreach as part of the curriculum can enhance these skills. Local outreach can be an important part of a global health curriculum, and also enables residents who may not have access to international electives, to gain additional clinical experience. Local outreach fosters a similar enthusiasm for providing access to care for an underserved community and can allow for longitudinal participation without the need to be away from the home institution for the number of days required to participate in an international elective. Of our respondents, local outreach is currently included in 10 programs (42\%). 


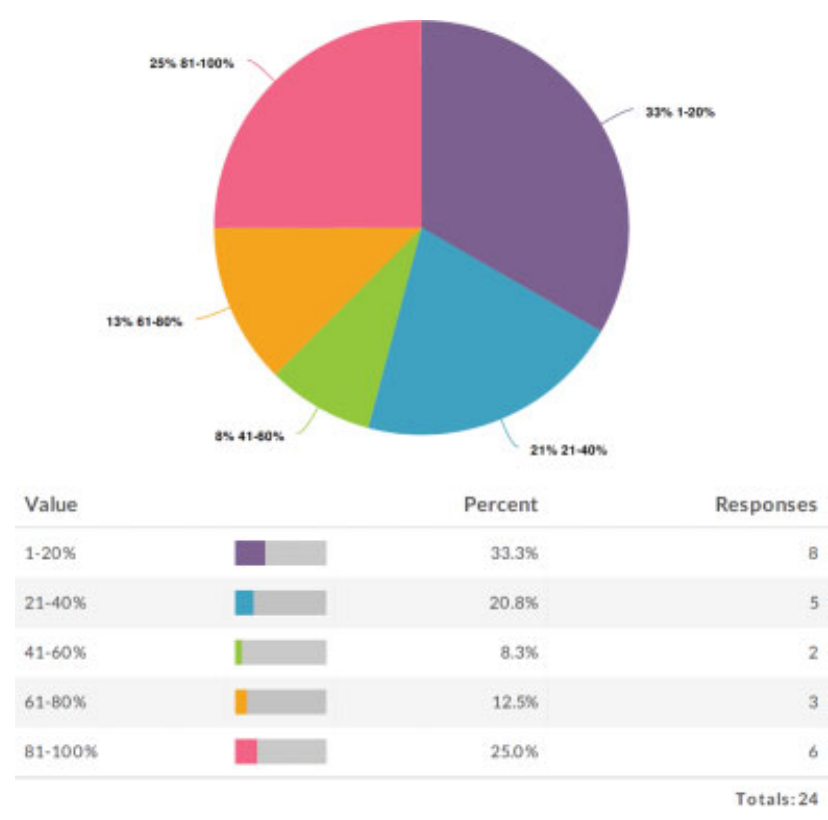

Fig. 2 Survey response regarding resident participation in global health curriculum.

The survey was administered in September of 2020 which took place during the COVID-19 pandemic. While the pandemic certainly affected global health curricula at residency programs, the COVID-19 pandemic further highlights the need for robust curricula at home institutions so that residents can be prepared for international global health oppor- tunities once it is safe to resume these activities. Survey respondents primarily described their global health curriculum before the onset of the pandemic as international travel was restricted, since most survey responses included answers regarding international electives.

This study was limited in its low response rate, which may increase response bias. There is also the possibility of response bias from program directors personally interested in global health or representing programs with robust global health curricula, which could cause misrepresentation of global health curricula across the country. Since the survey was administered during the COVID-19 pandemic to program directors, the unprecedented nature of the pandemic and its impact on the workload burden for program directors may have affected the survey response rate. Despite this, there was a fair distribution in geographic location and program-size of the respondents. To reduce the time burden of the survey and with the goal of increasing the response rate, the survey was generally limited to multiple-choice questions. This format may have limited some of the more nuanced details to describe a program's global health curriculum.

The survey reveals that resident time constraint still remains a barrier to implementing global health curricula. For those programs that do have global health elements, a majority of the activities in their curricula occur at most two times a year. Recognizing that there are many demands on our residents' time, we at BUSM have designed a curriculum that is administered over a 3-year period with the goal of training ethical, clinical, and surgical

\section{Does your global health curriculum include ethics related topics?}

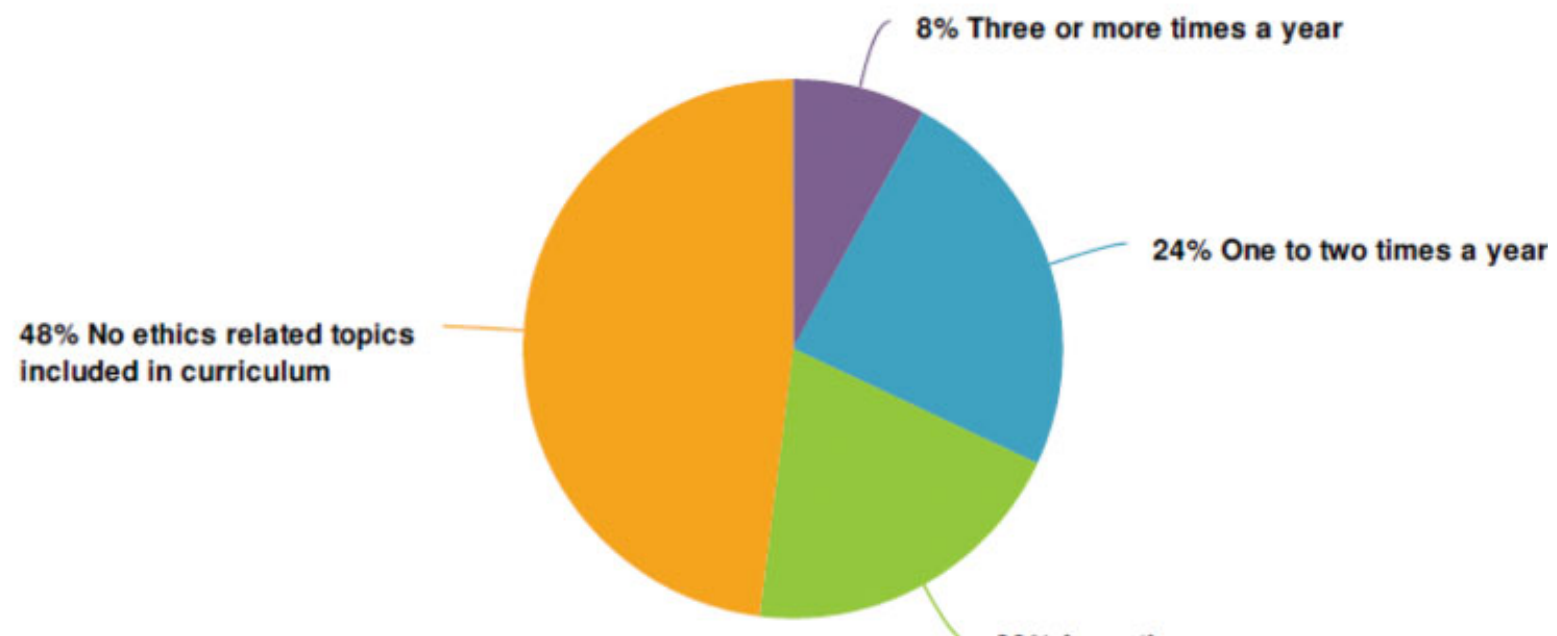

$20 \%$ Less than once a year

Fig. 3 Survey response to inclusion of ethics-related topic in global health curriculum. 


\section{What is the focus of your global health curriculum? Please check all that apply.}

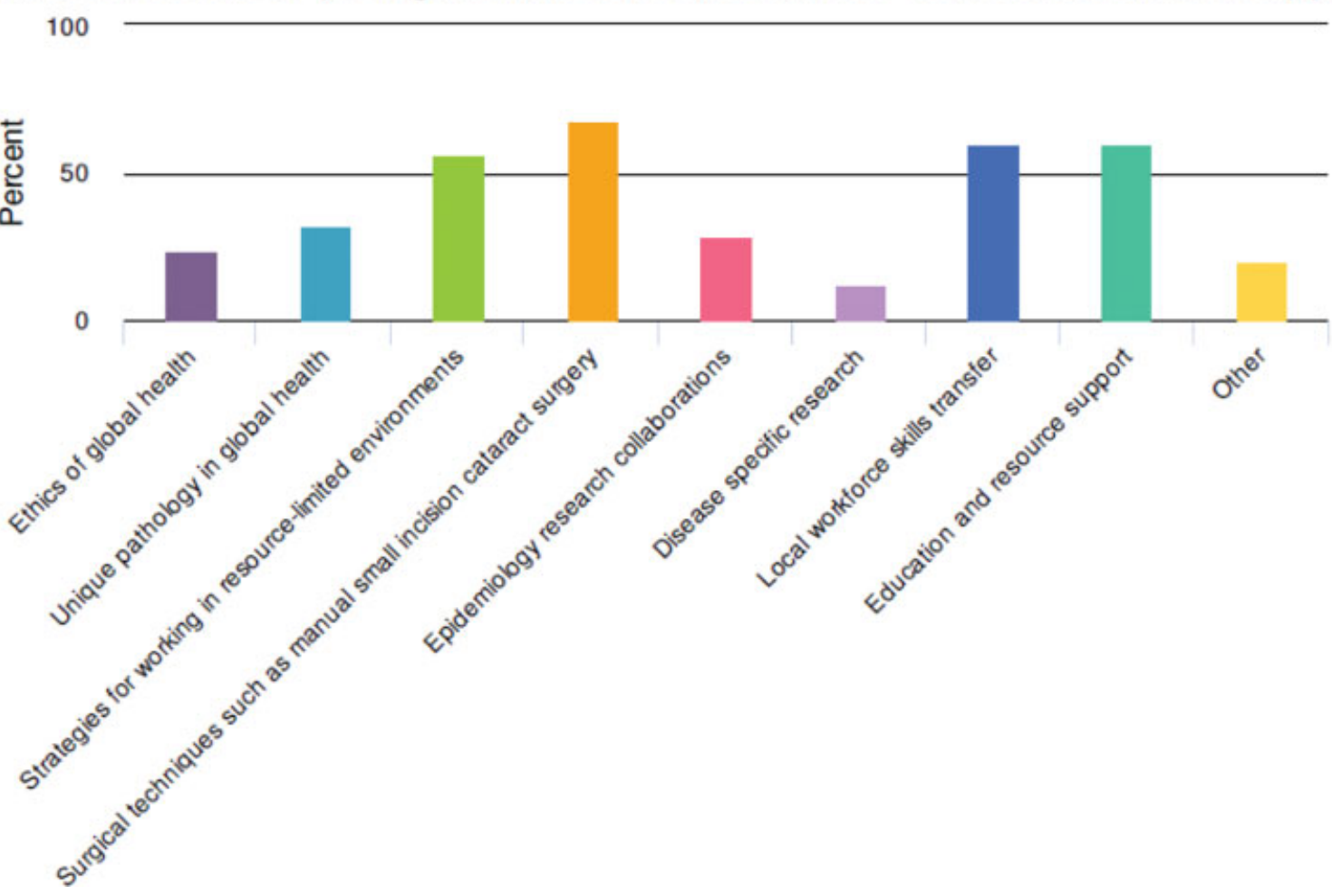

Fig. 4 Survey response to focus of global health curriculum.

ophthalmologists who will continue to give back locally and internationally. The curriculum has been designed with the ACGME core competencies in mind, to ensure that this adjunct learning is enhancing our residents' overall educational experience. The ACGME core competencies met through our curriculum are listed in - Fig. 5. Additionally, in this era of diversity, equity, and inclusion, a global health curriculum such as ours allows for an extension of this initiative. Residents who choose to participate attend 12 lectures, three journal clubs, three wet laboratories, two local outreach opportunities, and one international elective over the course of 3 years. This amounts to an activity approximately every other month during the course of their training, which allows for continuity of their global health education. The lecture series covers a variety of topics, including the epidemiology of visual disability globally, emerging infectious diseases of the eye, the similarities and differences in cataracts seen in resource-scarce areas, and glaucoma management in the setting of limited longitudinal follow-up. Journal clubs focus on the challenges of providing care in resource-limited settings and the ethics of international mission trips with attention to trainee involvement and sustainability. Wet laboratories are predominantly focused on MSICS, with the goal of third-year residents reaching competency to help lead the instruction of their junior residents in the wet laboratory. This model facilitates teaching of skills, which is important for the ongoing cross-cultural education and exchange they will experience throughout their careers. Local outreach experiences in the form of screening programs foster engagement and provide residents and medical students with exposure to the challenges of health care in marginalized and underserved communities. International trips take place during the third year of residency under the supervision of a faculty member. A pre-departure meeting and post-trip departmental presentation to share their experiences and reflections are required. Faculty formally evaluate the resident's understanding of the individual and system challenges during this presentation. This assessment integrates well within the existing core competencies and likely helps the resident understand healthcare systems in their home institution. Despite our efforts to mitigate time constraints, we acknowledge that our curriculum may still demand a significant amount of time on the parts of both the residents and faculty. However, we have found enthusiastic participation on both sides in the early stages of its implementation. We hope that as programs continue to develop and implement curricula, we can collaboratively learn from one another to improve our training and meet our residents' educational needs. 
e190 Global Health Curricula in Ophthalmology Residency Programs Ponsetto et al.

\section{ACGME Core Competencies}

Patient Care

Observe and compare public health systems in underserved populations locally and abroad Develop an understanding of health access inequities and learn to be a patient advocate in minimizing those disparities

Incorporate considerations of cost and resource availability into administration of eye care

Medical Knowledge

Learn the manifestations, management and prevention of malnutrition in eye disease

Develop familiarity with the presentation, diagnosis, management, and prevention of common infectious eye diseases in developing countries

Determine interventions that have been made or could be made in the prevention of eye disease

Interpersonal and Communication Skills

Develop cross-cultural knowledge and effective communication skills in the face of language and cultural barriers

Learn the local health practices to facilitate a cross-cultural exchange of ideas and skills

Recognize each role in the team involved in delivering access to eye care in underserved communities

Professionalism

Understand the ethical issues posed by global health initiatives, including the role that trainees play in providing healthcare and the quality of care given

Recognize the resource provided by local doctors with valuable expertise in endemic disease

Practice-Based Learning

Recognize the challenges of conducting clinics and surgeries in resource limited areas, and learn how to do so safely and efficiently to provide maximal benefit

Observe the administrative duties involved in establishing and running mission trips in resourcelimited settings

Systems-Based Practice

Reflect on the social, political, and economic influences on eye health

Build relationships with healthcare and governmental organizations abroad

Identify governmental and not-for-profit global health organizations and the impact that they have on health care policy

Recognize which strategies in the administration of eye care in resource-limited areas are effective and which are not

Fig. 5 ACGME core competencies met by BUSM global health curriculum. ACGME, Accreditation Council for Graduate Medical Education; BUSM, Boston University School of Medicine. 


\section{Abbreviations}

$\begin{array}{ll}\text { AUPO } & \begin{array}{l}\text { Association of University Professors in } \\ \text { Ophthalmology }\end{array} \\ \text { BUSM } & \begin{array}{l}\text { Boston University School of Medicine } \\ \text { MSICS }\end{array} \\ \text { Manual small incision cataract surgery } \\ \text { U.S. } & \text { United States }\end{array}$

Conflict of Interest

None declared.

Acknowledgments

We would like to thank the Boston University Ophthalmology Department for its continued support of this research and the Association of University Professors in Ophthalmology for facilitating the survey process.

\section{References}

1 American Association of Medical Colleges. Medical School Graduation Questionnaire 2020 All Schools Summary Report. 2020. Access date is $1 / 5 / 21$ at: https://www.aamc.org/data-reports/ students-residents/report/graduation-questionnaire-gq

2 Bills CB, Ahn J. Global Health and Graduate Medical Education: a systematic review of the literature. J Grad Med Educ 2016;8(05): 685-691

3 Miller WC, Corey GR, Lallinger GJ, Durack DT. International health and internal medicine residency training: the Duke University experience. Am J Med 1995;99(03):291-297

4 Gupta AR, Wells CK, Horwitz RI, Bia FJ, Barry M. The International Health Program: the fifteen-year experience with Yale University's Internal Medicine Residency Program. Am J Trop Med Hyg 1999;61(06):1019-1023

5 Hau DK, Dipace JI, Peck RN, Johnson WD Jr. Global health training during residency: the Weill Cornell Tanzania experience. J Grad Med Educ 2011;3(03):421-424

6 Disston AR, Martinez-Diaz GJ, Raju S, Rosales M, Berry WC, Coughlin RR. The international orthopaedic health elective at the University of California at San Francisco: the eight-year experience. J Bone Joint Surg Am 2009;91(12):2999-3004

7 Sawatsky AP, Rosenman DJ, Merry SP, McDonald FS. Eight years of the Mayo International Health Program: what an international elective adds to resident education. Mayo Clin Proc 2010;85(08):734-741
8 Volsky PG, Sinacori JT. Global health initiatives of US otolaryngology residency programs: 2011 global health initiatives survey results. Laryngoscope 2012;122(11):2422-2427

9 Anspacher M, Frintner MP, Denno D, et al. Global health education for pediatric residents: a national survey. Pediatrics 2011;128 (04):e959-e965

10 Haq C, Rothenberg D, Gjerde C, et al. New world views: preparing physicians in training for global health work. Fam Med 2000;32 (08):566-572

11 Coombs PG, Feldman BH, Lauer AK, Paul Chan RV, Sun G. Global health training in ophthalmology residency programs. J Surg Educ 2015;72(04):e52-e59

12 Nelson BD, Lee ACC, Newby PK, Chamberlin MR, Huang CC. Global health training in pediatric residency programs. Pediatrics 2008; 122(01):28-33

13 Powell AC, Casey K, Liewehr DJ, Hayanga A, James TA, Cherr GS. Results of a national survey of surgical resident interest in international experience, electives, and volunteerism. J Am Coll Surg 2009;208(02):304-312

14 Powell AC, Mueller C, Kingham P, Berman R, Pachter HL, Hopkins MA. International experience, electives, and volunteerism in surgical training: a survey of resident interest. J Am Coll Surg 2007;205(01):162-168

15 Camacci ML, Cayton TE, Chen MC. International experiences during United States ophthalmology residency training: current structure of international experiences and perspectives of faculty mentors at United States training institutions. PLoS One 2019;14 (11):e0225627

16 Cunningham CT, Quan H, Hemmelgarn B, et al. Exploring physician specialist response rates to web-based surveys. BMC Med Res Methodol 2015;15:32

17 Duncan ND. The adequacy of response rates to online and paper surveys: what can be done? Assess Eval High Educ 2008; 33:301-314

18 Logar T, Le P, Harrison JD, Glass M. Teaching corner: "first do no harm": teaching global health ethics to medical trainees through experiential learning. J Bioeth Inq 2015;12(01):69-78

19 Stone GS, Olson KR. The ethics of medical volunteerism. Med Clin North Am 2016;100(02):237-246

20 Sheather J, Shah T. Ethical dilemmas in medical humanitarian practice: cases for reflection from Médecins Sans Frontières. J Med Ethics 2011;37(03):162-165

21 Justin GA, Custer BL, Ward JB, Colyer MH, Waller SG, Legault GL. Global Health Outreach by United States Ophthalmology Residency Programs: understanding of host country systems-based practice. Mil Med 2019;184(11-12):e642-e646 